Portland State University

PDXScholar

\title{
The Impact of Adverse Childhood Experience (ACEs), Future Adult Incarceration, and Poor Mental Health- A Literature Review
}

Letasi M. Burgess

Portland State University

Follow this and additional works at: https://pdxscholar.library.pdx.edu/honorstheses

Part of the Other Social and Behavioral Sciences Commons Let us know how access to this document benefits you.

Recommended Citation

Burgess, Letasi M., "The Impact of Adverse Childhood Experience (ACEs), Future Adult Incarceration, and Poor Mental Health- A Literature Review" (2021). University Honors Theses. Paper 1047.

https://doi.org/10.15760/honors.1073

This Thesis is brought to you for free and open access. It has been accepted for inclusion in University Honors Theses by an authorized administrator of PDXScholar. Please contact us if we can make this document more accessible: pdxscholar@pdx.edu. 
The Impact of Adverse Childhood Experience (ACEs), Future Adult Incarceration, and Poor Mental Health- A Literature Review

\author{
By: \\ Letasi Burgess \\ An undergraduate thesis submitted in partial fulfillment of the \\ requirements for the degree of \\ Bachelor of Arts \\ In \\ University Honors \\ And \\ Criminology \& Criminal Justice
}

Thesis Adviser

Kendra Harding

Portland State University 


\begin{abstract}
:
The Adverse Childhood Experiences (ACE's) study is about childhood experiences with abuse, neglect, household challenges, and adult life mental and physical well-being (Saunders, R., \& Lockhart, S., 2020). ACE's that were identified and studied were substance abuse; domestic violence; emotional and physical neglect; physical, emotional, and sexual abuse; mental illness; divorce/separation; and members of the home who have been incarcerated. This paper will be about how adults who have been or are incarcerated, as well as have or have had mental health issues, were impacted by adverse childhood experiences.
\end{abstract}




\section{Introduction:}

The Adverse Childhood Experiences (ACE's) study was completed by Kaiser Permanente from the year 1995-1997 in collaboration with the Centers for Disease Control and Prevention. Kaiser patients were prompted to fill out confidential surveys that asked questions about their childhood experiences with abuse, neglect, household challenges, and adult life mental and physical well-being (Saunders, 2020). This study revealed that many people suffered at least one ACE while growing up. The ACE's that were studied were substance abuse; domestic violence; emotional and physical neglect; physical, emotional, and sexual abuse; mental illness; divorce/ separation; and members of the home who have been incarcerated. The ACE's study has become a staple to other research. It has been replicated to find causes of other events that are not ACE's themselves, such as the link between ACE's and suicide rates, eating disorders, and physical health issues. This literature review will be about how adults who have been or are incarcerated, as well as have or have had mental health issues, were impacted by adverse childhood experiences.

\section{Childhood Development:}

Children's brains are like sponges. They soak up information that is given to them or presented around them. They are unaware and innocent, and it is essential that children are raised in environments that are safe, so they are able to learn productively. Many things in the home can stunt that growth, such as parental substance abuse, domestic violence, neglect, parental mental illness, parental incarceration, and divorce or separation. Children with high ACE scores are 
more likely to experience anxiety and depression, developmental delays, cognitive and socioemotional health issues, academic challenges, and specialized health needs (Saunders, 2020). By having these disabilities and difficulties, children struggle in school both academically and socially. This can increase their chances of getting bullied by their peers, and in trouble with both their school and the law. Medications and treatments are available to help treat some disorders such as Attention-Deficit Disorder, Attention-Deficit Hyperactivity Disorder, anxiety and depression. However they are not always accessible to the children who suffer with these mental health needs, which can then lead to more if not diagnosed or treated.

Drug offenses account for almost half a million incarcerated people (Sawyer, 2020). Children can be affected by illicit (meth, cocaine, heroin, etc.) and non-illicit drugs (tobacco, alcohol) prenatally, as well as after birth. When parents use these drugs or alcohol, it can affect the child negatively and give them disabilities such as Fetal Alcohol Syndrome (FASD), attention disorders, behavior problems, and more. "Parental alcoholism and drug use have been considered risk factors for children's behavioral and emotional difficulties and future drug use (Brook, J. S., \& Tseng, L. J., 1996). For example, Sher, Walizer, Wood, and Brent (1991) compared children of alcoholics (COAs) with non-COAs and reported that COAs had more psychiatric distress and less control of behavior than non-COAs. Also, COAs were more likely to have alcohol and drug problems when they grew up"(Brook, J. S., \& Tseng, L. J., 1996). Parental substance abuse has a major impact on children both before they are born and after, making it an adverse childhood experience.

Domestic violence can be physical, emotional, or sexual abuse that takes place in the home. About 43 percent of children are present during acts of domestic violence (Burcham, B. 
2018). Children who witness and/or are involved in domestic violence are at a higher rate of experiencing post traumatic stress disorder (PTSD), anxiety, depression, substance abuse, personality disorder, identity disorder, etc. Children can also experience life-long lasting trauma, such as brain development, specifically to parts like the hippocampus, amygdala, cerebral cortex and more. The hippocampus is in the frontal lobe of the brain and helps with memory, and the amygdala drives the brain's fight-or-flight response. Lastly, the cerebral cortex, which is the biggest part of the brain, is the center of control and information processing. An annual research review, by Martin H. Teicher and Jacqueline A. Samson, studies these parts of the brain and discovers what is troubled by domestic violence. They discovered that there is a countless amount of proof that childhood abuse is associated with brain structure and function (Teicher, M. H., \& Samson, J. A., 2016). Second, they also discovered that the type of maltreatment experienced, age it happened, and gender matter as well. Because of these factors, "they raise concerns about the alternative approach of counting up adverse childhood experiences to provide a simple composite score"(Teicher, M. H., \& Samson, J. A., 2016). This is important to note, as the severity of domestic violence can cause a lapse in the score for an ACE's test, making it a more complex scale than what it is already.

Children can be neglected both physically and emotionally by their parents. Physically, their parents could not be providing the food, clothing, and/or shelter that they need to grow. Emotionally, their parents are not available to provide the support needed. Rather they are the person who scolds their children the most or makes their feelings seem invalid, causing their mental health to become poor. In Mark Bellis' study, "Does continuous trusted adult support in childhood impart life-course resilience against adverse childhood experiences - a retrospective 
study on adult health-harming behaviors and mental well-being", he concluded that having continuous access to a trusted adult in childhood may dramatically reduce the impacts of childhood adversity on mental well-being (2017). Children are emotional and vulnerable, which means they can be taken advantage of easily. There is also emerging evidence that neglect in childhood may be as harmful as physical and emotional abuse (Norman, R. E., Byambaa, M., De, R., Butchart, A., Scott, J., \& Vos, T., 2012). Children will act out if they are being ignored and do not feel validated. It is important to show kids that they are cared about and teach them how to communicate in effective ways, so they are able to have healthy relationships in the future. Like other ACE's, both physical and emotional neglect can cause problems like anxiety, depression, and even suicidal thoughts. In Shanta R. Dube's study, "Childhood Abuse, Household Dysfunction, and the Risk of Attempted Suicide Throughout the Life Span Findings From the Adverse Childhood Experiences Study", it was proven that the risk of suicide attempt was increased two- to five-fold by any adverse childhood experience, regardless of the category (2001). There have been many studies on the suicide attempts of children and young adults, and many factors can lead to the attempt. In a study done by Lauma Springe, physical neglect was higher than physical violence and that latter posed a higher risk for attempted suicide (2016). All of the ACE's can be a factor in an attempted suicide, but neglect is a large cause of attempts in young people.

Acknowledging mental illness has become more popular and accepted within the past decade. Mental illness is slowly being accepted and treated more regularly, but it still holds a stigma. Stigmas include people being blamed for their actions when they have an illness that makes their actions uncontrollable like a panic attack, or general disapproval from society when 
someone shares or discovers they have mental health needs. Often people are born with mental health needs, have experienced trauma that has built up then led to it, or have used drugs that have contributed. No matter the origin, a majority of mental illnesses are able to be treated. Adults who are parents are no stranger to mental illness and have to deal with them while parenting. Up to one third of adults who access mental health services are parents caring for dependent children (Tchernegovski, P., Hine, R., Reupert, A. E., \& Maybery, D. J., 2018). Common examples of this would be, but not limited to postpartum depression, depression, and anxiety. Parenting is difficult enough, but those who have a mental illness struggle the most with things such as emotional availability for their children. Not all parents with mental illness display the same degree of parenting difficulty. Those with more severe and chronic disturbance were associated with less sensitive and competent parenting behaviors than parents with less debilitating disturbances (Reupert, A., \& Maybery, D., 2007). Mothers and fathers who display these illnesses can make their children develop anxiety, depression, and other illnesses early on. "Adolescents and adults who experienced multiple childhood adversities are more likely to experience mental illness and adopt unhealthy later-life behaviors as coping mechanisms" (Kerker, B. D., Zhang, J., Nadeem, E., Stein, R. E., Hurlburt, M. S., Heneghan, A., ... \& Horwitz, S. M., 2015). Examples of coping mechanisms would be drug abuse, alcohol abuse, violence, unsafe sex, etc. Along with mental illness, children have poor physical health and poor social development. In addition, an increased number of ACE's were associated with an increased risk of learning or behavioral disorders and a high body mass index among children and adolescents (Kerker, B. D., Zhang, J., Nadeem, E., Stein, R. E., Hurlburt, M. S., Heneghan, A., ... \& Horwitz, S. M., 2015). Parents who have experienced adverse childhood experiences themselves are more 
likely to continue those habits onto their children unintentionally, especially if they have not been able to receive the treatment that they need in order to heal from their own trauma.

Incarceration affects not only the incarcerated person, but their friends and family who care for and love the incarcerated person. The United States alone has some of the highest incarceration rates in the world; one in twenty-three adults are under some form of state control such as jail, prison, probation, parole, community sanctions, drug courts, immigrant detention, and other types of government supervision. To add to this, one in ten children has had an incarcerated parent (Kappeler, V. E., \& Potter, G. W., 2017). Children are not only affected by the incarceration of their parents here in the United States, they are affected all over the world. Daragh Bradshaw's research in Ireland concludes that the stigma associated with parental incarceration can compromise the child's social and community interactions (Bradshaw, D., Hannigan, A., Creaven, A. M., \& Muldoon, O. T., 2020). In addition, early behavioral issues can increase the risk for later difficulties such as antisocial personality disorder and crime in early adulthood. These effects are particularly relevant for children who have exposure to early psychosocial adversity such as parental incarceration (Bradshaw, D., Hannigan, A., Creaven, A. M., \& Muldoon, O. T., 2020). Each of the children in the one in ten statistics in this study are at risk of developing a disorder or mental illness everywhere in the world. In some places such as Tacoma, Washington and Wilsonville, Oregon there are programs at the women's prisons that offer programs where the mother can still be mothers from prison. The program at Coffee Creek in Wilsonville allows children to have sleepovers in the prison, and the program at Washington Corrections Center for women in Tacoma provides a nursery for the new moms to keep their babies in. While there are not any programs for men and fathers specifically, this is a step in the 
right direction of creating better relationships between incarcerated parents and their children. These programs also lessen the severity of the adverse childhood experience of parental incarceration.

The divorce and separation of parents is devastating to any child. Children are naive and believe their parents will stay together forever. When that does not happen, it can negatively affect the child and their development. More than one million children experience the divorce of their parents every year in the United States, making divorce involving children a question of public health (Vezzetti, V. C., 2016). This study also discovered that early parental separation has stronger and wider effects on adult psychopathology. Maternal and paternal separations were almost equally associated with most forms of psychopathology, and parental separation had the strongest impacts on risk for depression and drug abuse/dependence (Vezzetti, V. C., 2016). In addition to these risks, children of divorced parents have poorer academic performance, are more likely to engage in delinquent behavior and early sex, and to exhibit emotional distress and academic difficulties (Clarke-Stewart, K. A., Vandell, D. L., McCartney, K., Owen, M. T., \& Booth, C., 2000). Divorce and separation is detrimental to a child's development, and they need the extra support and care from both parents in order to not become a statistic. Having support from both sides will not fix all of their problems, but it will help limit the adverse childhood experience that will make them a more successful and healthy child.

\section{Financial Wellness:}

Child development is extremely important to ensure that children are able to live a successful and healthy adult life. Financial wellness and stability can be affected if a child does not receive the emotional or physical support that they need. This can put them in difficult 
situations, such as living in poverty or being homeless in their adulthood. They also are more at risk of not finishing high school or continuing their education after graduating. If a child has adverse childhood experiences, then the chances of this happening are higher than a child who did not experience any.

Poverty is the most pressing public health issue facing the state, as it negatively impacts nearly every indicator of child well-being and affects more than one in five children (Hughes, M., \& Tucker, W., 2018). Many American households fall under or at the poverty line. With the lack of jobs and the cost of living being expensive, those who were not able to continue school after high school can not find jobs with a livable wage. Previous research on the impact of poverty on parenting stress has shown that low income is linked specifically to parental distress (Steele, H., Bate, J., Steele, M., Dube, S. R., Danskin, K., Knafo, H., ... \& Murphy, A., 2016). Poverty has effects on both the child and the parent. Unfortunately many people who grow up in poverty stay in poverty, which increases stress levels in the child. The parents worry about giving to the child before themselves, which is difficult because a person can only go without for so long. In Leanne Whiteside-Mansell's study, “Adverse Childhood Experiences of Urban and Rural Preschool Children in Poverty", she states that children living in poverty are more susceptible to ACE exposure (Whiteside-Mansell, L., McKelvey, L., Saccente, J., \& Selig, J. P., 2019). When adults go without and cannot provide for their children, it leads to distress which can lead to the distress of the child/children. This can cause abuse, neglect, and separation which then leads to issues in a child's emotional and physical health, as well as trouble with their development. Without help from communities and governments, poverty will lead to mass houselessness of men, women, and children. 
Houselessness is a booming problem in the United States. It seems like there is a tent on every corner or someone on the side of every highway begging for change. Houselessness may be associated with multiple stressors, including poverty, poor family functioning, instability, contact with illicit substances, exposure to community violence, risks related to general safety and well-being, and loss of opportunities such as education, and routine health care (Radcliff, E., Crouch, E., Strompolis, M., \& Srivastav, A., 2019). Experiencing houselessness as a child is traumatizing, and it could lead to houselessness in adulthood. In Ann Elizabeth Montgomery's study, "Relationship among adverse childhood experiences, history of active military service, and adult outcomes: homelessness, mental health, and physical health", she concluded that adults who reported higher levels of childhood adversity were more likely to also experience adult homelessness (2013). Questionnaires were sent to people in the general population and using a population-representative sample, the findings reported here confirm the links between adverse childhood experiences and adult homelessness (2013). This is important, because it highlights the importance of adverse childhood experiences and how children unfortunately have to suffer through them.

\section{Intimate Partner Violence:}

Intimate partner and domestic violence have been recognized more within the past decade, and new laws and regulations have been implemented because of it (Bridges, F. S., Tatum, K. M., \& Kunselman, J. C., 2008). Domestic violence can be committed by a family member or an intimate partner. Family members include mothers, fathers, siblings, stepparents, stepchildren, etc. An average of three and a half people are killed by intimate partners everyday in this country, and approximately 45,500 intimate partner homicides between 1981 and 1998 . 
Furthermore, each year about one in three female homicides and one in twenty male homicides were committed by spouses, ex-spouses, or boyfriends (Bridges, F. S., Tatum, K. M., \& Kunselman, J. C., 2008). Violence in the home and homicide do not only happen to women, but there is a much smaller ratio of men to women victims. Also, there are same sex couples that need to be considered. There have been more resources within the last decade for men and women to access when they are victims of domestic violence such as shelters, hotlines, and support groups. However, it is still difficult to get out of those types of relationships. The people who commit these crimes usually are the victim to or witness violence as a child. "Findings suggested that a range of adverse childhood events are associated with intimate partner violence behaviors, consistent with other research" (Nikulina, V., Gelin, M., \& Zwilling, A., 2021). Some people do not know how to move past the experiences they had as a child and they continue these experiences on to their family and partners, sometimes creating experiences worse than their own.

Domestic violence accounts for over 20 percent of all violent crime against women, and recent national statistics show that almost one third of female murder victims in this country were killed by an intimate partner (Bridges, F. S., Tatum, K. M., \& Kunselman, J. C., 2008). The Violence Against Women Act (VAWA) was enabled in 1994 and continues to be renewed every few years. One of its biggest parts of this act is for anyone who has committed domestic violence, it is a federal offense to own a firearm. Women are not the only victims of domestic violence, but women are affected at a higher rate than men. "Although there are clear social benefits to averting both the murder of men and the likely incarceration of the female perpetrator, the null female findings suggest that policy enhancements are needed to dramatically increase 
the safety of women in relationships with men"(Dugan, L., Nagin, D. S., \& Rosenfeld, R., 2003). Domestic violence does not always lead to the victim being murdered, but it does happen enough for there to be concern and studies done on it to solve this problem. There are many resources available for women so they are able to leave and still support themselves and their children to an extent. These resources include restraining orders and food stamps, but that is not always enough to protect them. "Substantial evidence shows that the highest homicide risk is during the period when a battered victim leaves the relationship, suggesting a potential "retaliation effect" from exposure reduction associated with domestic violence interventions" (Dugan, L., Nagin, D. S., \& Rosenfeld, R., 2003). This behavior is learned from adverse childhood experiences. "Maltreated children are at risk for subsequent psychological, behavioral, and physical problems; this includes aggression, violence...”(Whitfield, C. L., Anda, R. F., Dube, S. R., \& Felitti, V. J., 2003). Domestic violence is becoming more apparent to the public, and it is important to make a change to eliminate it from happening to women, children, and men all over the world.

Men are victims of intimate partners and domestic violence as well. 1.3 men per 1,000 are victims of intimate partner violence each year (Shuler, C. A., 2010). Because of feminist movements and protests, men have a harder time being believed that they have been a victim too. Caroletta A. Shuler also states that "this societal conflict has resulted in the argument that, if males are victims of domestic violence, then it is due to the self-defense of women being abused"(2010) which is not always true. A more modern example of this would be the Amber Heard and Johnny Depp case, where she was caught on camera and audio recordings being the abuser. In general, men tend to not report these cases because they feel as if they need to be strong like a stereotypical man and that women are not supposed to overpower them. Violence 
against women is seen more seriously than violence against men, and many men fear that seeking help would label them as aggressor, especially if they defend themselves. This double standard view in society has resulted in many male victims not seeking the assistance of law enforcement (Shuler, C. A., 2010). There are not many places that men who are victims of intimate partner or domestic violence can go, and there is also not much information on how to help victims who are men. Men and women both can be abusers, and they both can have similar childhood experiences that have gotten them to behave and treat the people that they love in this way.

Same sex couples experience episodes of intimate partner and domestic violence. Despite the myth that intimate partner violence (IPV) is exclusively an issue in heterosexual relationships, many studies have revealed the existence of IPV among lesbian and gay couples. Its incidence is comparable to or higher than that among heterosexual couples (Rollè, L., Giardina, G., Caldarera, A. M., Gerino, E., \& Brustia, P., 2018). In addition, over 50 percent of gay men and almost 75 percent of lesbian women reported that they were victims of psychological IPV (Rollè, L., Giardina, G., Caldarera, A. M., Gerino, E., \& Brustia, P., 2018). Psychological violence is not the only type that is experienced, physical and sexual abuse are also experienced in same sex relationships. Like men and women in heterosexual relationships, anybody could have experienced domestic violence as a child and learned to act violent from those experiences. Because same sex marriage was illegal for so long, there is minimal research done on IPV in same sex couples but the research on is continuing to grow. In "A Comparison of the Police Response to Heterosexual Versus Same-Sex Intimate Partner Violence” by April Pattavina, she discovered that mandatory-arrest policies increase the likelihood of arrest more for 
female same-sex couples than for male same-sex couples. This is likely because there is greater advocacy of female victims than male (2007). This is important to note, because it highlights how men are not as cared for by the justice system when it comes to domestic violence situations. "These findings underscore the importance of considering the gender of same-sex couples as a separate category in studies of intimate partner violence and bolster the need to advance research in this area to identify other political, cultural, situational, and individual characteristics that may account for the differences among groups observed in this study" (Pattavina, A., Hirschel, D., Buzawa, E., Faggiani, D., \& Bentley, H., 2007). Domestic or intimate partner violence can happen in any type of relationship, and it is possible for people to not get the justice they deserve. The violence and aggression needs to be addressed at an early age so nobody is victimized by this crime.

\section{Adult Substance Abuse:}

Substance abuse is a growing epidemic that has impacted everyone in some way. People become addicted to painkillers that become unaffordable, and then it leads to a cheaper alternative like meth or heroin. After kids are introduced to drugs like cocaine and Xanax, they then have to use them just to function every day in work and school. This can later lead to worse drugs later on in their lives. "Opioid overdose deaths have increased at an alarming and accelerated rate; from 2015-16, for instance, deaths due to opioid overdose increased 27.7\% [ㄹ] Opioid overdose mortality and its associated economic burden have been among the major consequences of this epidemic; in 2014, for instance, $61 \%$ of drug overdose deaths involved opioids" (Yang, J. C., Roman-Urrestarazu, A., \& Brayne, C, 2020). Even substances like nicotine and alcohol are highly addictive and can cause death. Anyone can become addicted to drugs or 
alcohol, and it is a vicious cycle to break free from. There are many other things that can lead to drug or alcohol abuse, such as a close death, child abuse, child neglect, mental illness, etc. In the article, "Molested as children: A hidden contribution to substance abuse?", Damaris Rohsenow states that child sexual abuse may be a hidden factor in the history of a substance abuser that is contributing significantly to the continuance of the substance abuse or to rapid relapse after treatment (1988). People who suffer trauma like sexual abuse do not always know how to cope with it in a healthy way. Sexual abuse victims who later turn to substance abuse may be using alcohol or drugs to cope with some of the long-term effects of the sex abuse. These include the sense of powerlessness, low self-esteem, and social isolation resulting from their damaged sense of self, impaired social skills, and inability to trust others (Rohsenow, D. J., Corbett, R., \& Devine, D., 1988). This adverse childhood experience is a serious cause of adult substance abuse and it is important that these people are treated effectively, and that this behavior does not lead to more children experiencing this and abusing substances as well.

Alcoholism is most prevalent in the age group of 18-44, when many individuals are getting married and having families (Gruber, K. J., \& Taylor, M. F., 2006). Many events can lead to alcohol use and abuse like peer pressure, depression, anxiety, etc. Children who grow up with an alcoholic parent are at increased risk of abusing alcohol (Gruber, K. J., \& Taylor, M. F., 2006). Family is a big part of substance use and abuse, and they can play different roles in the process like introduction to substance, enablers, or support system for recovery. Whatever the role may be, it is important to establish what is needed to get the abuse under control, which may not be through family. Having parents with a disorder not only increases the chance of a disorder in the child's own future, but child abuse potential may be increased when a parent is affected by a 
substance abuse disorder (Gruber, K. J., \& Taylor, M. F., 2006). Women who are pregnant and continue drinking can cause Fetal Alcohol Syndrome or other disabilities for their unborn child, another form of child abuse. One widely cited estimate suggests that one in four children in the United States under the age 18 is exposed to alcohol abuse or dependence in their family (Gruber, K. J., \& Taylor, M. F., 2006). This is a big ratio, and this continues to add to the number of children encountering adverse experiences leading to more problems for them down the road.

Tobacco and nicotine have been a common drug that younger and older people have gotten addicted to. Smoking cigarettes used to be popular in the 1960's and they were allowed to be smoked in planes, cars, restaurants, etc. Within the last decade, cigarette popularity has turned to vape popularity among kids, teens, and adults. According to one national survey, 3.6 million middle and high school students used e-cigarettes in 2018 (Hoffman, J., 2018). Nicotine is highly addictive and people all over have been becoming addicted because of the convenience companies have turned consuming nicotine into. Up until the recent ban, many vapes came in different flavors, discreet pens so they are easy to hide, and do not produce a smell when in use. Kids and teens are introduced to this at school, social events, and at home. "Genetic factors also influence the risk of nicotine dependence"(Prochaska, J. J., \& Benowitz, N. L., 2019). Mental illness commonly co-occurs with tobacco addiction, including major depression, bipolar disorder, post-traumatic stress disorder (PTSD), and schizophrenia (Prochaska, J. J., \& Benowitz, N. L., 2019). When parents have these illnesses, it makes it harder for them to parent their children and can cause them to do it in an unhealthy way. As stated before, many children have this adverse experience of neglect or abuse due to substance abuse, which can also be passed on 
to them genetically. Smoking tobacco products are gateway drugs that can affect a child's development, and a parent's relationship with their children.

Along with alcohol and tobacco products, addiction to opioids, narcotics, stimulants, and more affects children who have grown up around or in it. Addiction is a disease, and it can be passed on through generations. Studies of the children of alcoholics and drug abusers suggest that there may be long-term negative effects of growing up in a substance abusing family. These include intergenerational substance abuse; adult adjustment problems, especially in the area of intimate relationships; and a general inability to move beyond the early adverse experiences (Gruber, K. J., \& Taylor, M. F., 2006). Addiction can lead to aggressive behaviors to the users themselves, as well as their children because that is something they have continued to witness and learn from. "An aggressive and impulsive teenager is at higher risk for substance abuse" (Tripathi, B. M., \& Lal, R., 1999). When children and teenagers experience abuse and/or neglect, it can lead to them abusing substances as well. Children learn from their parents, and adverse childhood experiences that parents put them through affect the way that they grow up. These experiences have a huge impact on whether or not the child becomes a substance abuser like they are, and they will likely develop the other traits that come along with it.

\section{Adult Mental Health:}

It is safe to say that a majority of adults have had or currently have struggles with their mental health. Everyday things like work, family, friends, politics, global warming, and anything else that might be concerning to a person can cause depression, suicidal thoughts or can trigger or cause post traumatic stress disorder (PTSD). There are many types of mental illness, but these are some of the more common ones that people deal with. ACE's have strong and dose-wise 
associations with increased risk of fair or poor health and psychological distress (Huang, Y., Liu, H., \& Masum, M., 2020). Not only do ACE's affect mental health, but it also affects physical health. Adverse childhood experiences have a detrimental effect on children's health, and if these issues are not fixed early on, the illness can continue to adulthood. The sooner the issues are addressed, the less trouble individuals will get into in the long run.

There are many different kinds of depression that a person can be diagnosed with. Some examples include major depressive disorder (MDD), persistent depressive disorder (PDD), and bipolar disorder. "Childhood adversity is predictive of an increased prevalence of lifetime and recent depressive disorders in adulthood"(Poole, J., 2016). Not all children who experience adversity will develop depression as adults, but many do as a result of the length and severity of the adverse experience(s). Individuals who demonstrate stable and healthy levels of functioning despite experiences of adversity are commonly referred to as "resilient"(Poole, J., 2016). While people are capable of healing from adverse experiences, there are still people who are not as successful at healing or it takes them longer to do so. There is an average loss of 28.9 years of quality-adjusted life expectancy for depressed individuals, which by comparison is at least twice the burden of several chronic conditions, such as stroke, heart disease, diabetes mellitus, hypertension, and asthma (Merrick, M. T., Ports, K. A., Ford, D. C., Afifi, T. O., Gershoff, E. T., \& Grogan-Kaylor, A., 2017). Depression is a severe disorder that can have worse effects on someone than a physical health disorder can which is alarming. Depression is also a leading risk factor of suicide, which is one of the leading causes of death in the United States (Merrick, M. T., Ports, K. A., Ford, D. C., Afifi, T. O., Gershoff, E. T., \& Grogan-Kaylor, A., 2017). Victims of 
depression need to be treated with care and kindness and treatment options need to be more available to those who need it.

In her study, “All Unhappy Childhoods Are Unhappy in Their Own Way - Differential Impact of Dimensions of Adverse Childhood Experiences on Adult Mental Health and Health Behavior", Anna L. Westermair discovered that maltreatment and sexual abuse predicted PTSD, bipolar disorder, and suicidal behavior (2018). Suicidal behavior has become more apparent, especially during this pandemic. People who have experienced things like emotional, sexual, and/or physical abuse, as well as emotional and/or physical neglect as a child are more likely to have suicidal behaviors. There are many mental health facilities and treatment centers that help with people who are having these thoughts, as well as a hotline that is available to call if in need or immediate assistance. Suicide prevention tactics are strategic and must be well organized to help the individual in need. A study, "The Association Between Adverse Childhood Experiences (ACEs) and Suicide Attempts in a Population-Based Study" by E. Fuller-Thompson proved that the population attributable risk fraction of sexual abuse to a history of suicide attempts is substantially greater in females than males (2016). Females are victims of abuse more than men both as children and adults, which can lead to suicidal thoughts and committing suicide. Age and gender are also connected when it comes to suicide. According to Chris Girard's article, “Age, Gender, and Suicide: A Cross- National Analysis", he concluded that suicide rates peak early in adulthood and that the rates may be equal to or more for young women than men (1993). Suicide is a tragic act, and it is important to help people before it is too late.

Post traumatic stress disorder can be caused by many things such as abuse, neglect, going to war, drugs, etc. In a study done by TN Brockie, abuse and neglect, witnessing violence against 
one's mother, historical loss associated symptoms, and discrimination are common and strongly linked to depression symptoms, poly-drug use, PTSD symptoms, and suicide attempt (2015). PTSD is not easy to treat, but help is available such as counseling or support groups to get through it. In the research article, "Type and timing of adverse childhood experiences differentially affect severity of PTSD, dissociative and depressive symptoms in adult inpatients", it is discovered that PTSD, the most severe stress related disorder, clearly varies with the amount of adverse experiences irrespective of age of experience (Schalinski, I., Teicher, M. H., Nischk, D., Hinderer, E., Müller, O., \& Rockstroh, B., 2016). PTSD can be developed at any age and the amount of adverse experiences and the seriousness of them determines how bad the disorder is for an individual. Many people suffer from this disorder, and it is essential that people have ways to cope and have the support from people of similar experiences to help live with the disorder.

\section{Adult Incarceration:}

All of these adverse childhood experiences can lead to a rough adult life. Unfortunately, a lot of people with these experiences can end up in jail or prison, and tend to come back because the justice system is not set up to allow criminals to change for the better. In the study, Adverse Experiences, Mental Health, and Substance Use Disorders as Social Determinants of Incarceration, by Brandy F Henry, participants described how social isolation leads to depression and anxiety that contributed to substance use as an escape and described how mental health and substance use disorders were connected to their crimes, either through inhibited judgment or emotional release (2020). Adverse experiences and their severity can cause these individuals to commit crimes and land them in institutions. Many people are incarcerated for substance abuse issues which can sometimes lead to other crimes like robbery, assault, and even homicide. Also, 
people who are homeless and/or have a mental illness are incarcerated for committing similar crimes. Incarcerated people with co-occurring substance-related disorders and severe mental disorders had higher rates of violent charges than those without dual diagnoses, regardless of whether or not they were homeless (Ross, J., Waterhouse-Bradley, B., Contractor, A. A., \& Armour, C., 2018). In another study, it was predicted that incarceration during adulthood with certain typologies who experienced childhood adversities associated with an approximately oneto threefold increased risk, after accounting for sociodemographic and substance use disorders

(Roos, L. E., Afifi, T. O., Martin, C. G., Pietrzak, R. H., Tsai, J., \& Sareen, J., 2016). People who have experienced adverse childhood experiences are at a higher risk of committing crimes than someone who has not had any adverse experiences. These men and women act out and break the law because they were never able to heal from their trauma, and they have found unhealthy ways to cope with it.

\section{Conclusion:}

More than one half of the general population has been shown to experience at least one ACE, over a quarter experience two or more ACEs, and one eighth experience four or more ACEs (Saunders, R., \& Lockhart, S., 2020). Due to this, people who have experienced one or few of these traumas become incarcerated because of their unhealthy coping mechanism. People who lived through adverse childhood experiences are likely to suffer at an increased rate from mental illness and substance abuse, which also get them incarcerated. There have been many studies and programs done and created to help those who have been victimized by ACE's, and there will continue to be more as new facts are discovered. Adverse childhood experiences affect both mental and physical health and it is crucial that these cycles of family abuse, neglect, 
incarceration, separation, and mental illness are stopped and not traumatizing anymore people. Be aware, be kind, and be mindful of people who have these traumas. Get involved on how to support them and put a stop to adverse experiences everywhere. 


\section{Works Cited:}

1. Bellis, M. A., Hardcastle, K., Ford, K., Hughes, K., Ashton, K., Quigg, Z., \& Butler, N. (2017). Does continuous trusted adult support in childhood impart life-course resilience against adverse childhood experiences-a retrospective study on adult health-harming behaviours and mental well-being. BMC psychiatry, 17(1), 1-12.

2. Bradshaw, D., Hannigan, A., Creaven, A. M., \& Muldoon, O. T. (2020). Longitudinal associations between parental incarceration and children's emotional and behavioural development: Results from a population cohort study. Child: care, health and development, 46(2), 195-202.

3. Bridges, F. S., Tatum, K. M., \& Kunselman, J. C. (2008). Domestic violence statutes and rates of intimate partner and family homicide: A research note. Criminal Justice Policy Review, 19(1), 117-130.

4. Brockie, T. N., Dana-Sacco, G., Wallen, G. R., Wilcox, H. C., \& Campbell, J. C. (2015). The relationship of adverse childhood experiences to PTSD, depression, poly-drug use and suicide attempt in reservation-based Native American adolescents and young adults. American journal of community psychology, 55(3-4), 411-421.

5. Brook, J. S., \& Tseng, L. J. (1996). Influences of parental drug use, personality, and child rearing on the toddler's anger and negativity. Genetic, social, and general psychology monographs, 122(1), 107-128.

6. Burcham, B. (2018). Domestic Violence and Children: How Does Trauma Severity Affect Development? (Doctoral dissertation, Alliant International University). 
7. Clarke-Stewart, K. A., Vandell, D. L., McCartney, K., Owen, M. T., \& Booth, C. (2000). Effects of parental separation and divorce on very young children. Journal of Family Psychology, 14(2), 304.

8. Dube, S. R., Anda, R. F., Felitti, V. J., Chapman, D. P., Williamson, D. F., \& Giles, W. H. (2001). Childhood abuse, household dysfunction, and the risk of attempted suicide throughout the life span: findings from the Adverse Childhood Experiences Study. Jama, 286(24), 3089-3096.

9. Dugan, L., Nagin, D. S., \& Rosenfeld, R. (2003). Exposure reduction or retaliation? The effects of domestic violence resources on intimate-partner homicide. Law \& society review, 37(1), 169-198.

10. Fuller-Thomson, E., Baird, S. L., Dhrodia, R., \& Brennenstuhl, S. (2016). The association between adverse childhood experiences (ACEs) and suicide attempts in a population-based study. Child: care, health and development, 42(5), 725-734.

11. Girard, C. (1993). Age, gender, and suicide: A cross-national analysis. American sociological review, 553-574.

12. Gruber, K. J., \& Taylor, M. F. (2006). A family perspective for substance abuse: Implications from the literature. Journal of Social Work Practice in the Addictions, $6(1-2), 1-29$.

13. Henry, B. F. (2020). Adverse experiences, mental health, and substance use disorders as social determinants of incarceration. Journal of community psychology, 48(3), 744-762. 
14. Huang, Y., Liu, H., \& Masum, M. (2020). Adverse Childhood Experiences and Physical and Mental Health of Adults: Assessing the Mediating Role of Cumulative Life Course Poverty. American Journal of Health Promotion, 0890117120982407.

15. Hughes, M., \& Tucker, W. (2018). Poverty as an adverse childhood experience. North Carolina medical journal, 79(2), 124-126.

16. Hoffman, J. (2018). How to Help Teenagers Quit Vaping. New York Times.

17. Kappeler, V. E., \& Potter, G. W. (2017). The mythology of crime and criminal justice. Waveland Press.

18. Kerker, B. D., Zhang, J., Nadeem, E., Stein, R. E., Hurlburt, M. S., Heneghan, A., ... \& Horwitz, S. M. (2015). Adverse childhood experiences and mental health, chronic medical conditions, and development in young children. Academic pediatrics, 15(5), $510-517$.

19. Merrick, M. T., Ports, K. A., Ford, D. C., Afifi, T. O., Gershoff, E. T., \& Grogan-Kaylor, A. (2017). Unpacking the impact of adverse childhood experiences on adult mental health. Child abuse \& neglect, 69, 10-19.

20. Montgomery, A. E., Cutuli, J. J., Evans-Chase, M., Treglia, D., \& Culhane, D. P. (2013). Relationship among adverse childhood experiences, history of active military service, and adult outcomes: Homelessness, mental health, and physical health. American journal of public health, 103(S2), S262-S268.

21.Nikulina, V., Gelin, M., \& Zwilling, A. (2021). Is there a cumulative association between adverse childhood experiences and intimate partner violence in emerging adulthood?. Journal of interpersonal violence, 36(3-4), NP1205-1232NP. 
22. Norman, R. E., Byambaa, M., De, R., Butchart, A., Scott, J., \& Vos, T. (2012). The longterm health consequences of child physical abuse, emotional abuse, and neglect: a systematic review and meta-analysis. PLoS med, 9(11), e1001349.

23. Pattavina, A., Hirschel, D., Buzawa, E., Faggiani, D., \& Bentley, H. (2007). A comparison of the police response to heterosexual versus same-sex intimate partner violence. Violence Against Women, 13(4), 374-394.

24. Poole, J. (2016). Adverse Childhood Experiences and Adult Depression: Resilience as a Moderator (Master's thesis, Graduate Studies).

25. Prochaska, J. J., \& Benowitz, N. L. (2019). Current advances in research in treatment and recovery: Nicotine addiction. Science advances, 5(10), eaay9763.

26. Radcliff, E., Crouch, E., Strompolis, M., \& Srivastav, A. (2019). Homelessness in childhood and adverse childhood experiences (ACEs). Maternal and child health journal, 23(6), 811-820.

27. Reupert, A., \& Maybery, D. (2007). Families affected by parental mental illness: A multiperspective account of issues and interventions. American Journal of Orthopsychiatry, 77(3), 362-369.

28. Rohsenow, D. J., Corbett, R., \& Devine, D. (1988). Molested as children: A hidden contribution to substance abuse?. Journal of substance abuse treatment, 5(1), 13-18.

29. Rollè, L., Giardina, G., Caldarera, A. M., Gerino, E., \& Brustia, P. (2018). When intimate partner violence meets same sex couples: A review of same sex intimate partner violence. Frontiers in psychology, 9, 1506. 
30. Roos, L. E., Afifi, T. O., Martin, C. G., Pietrzak, R. H., Tsai, J., \& Sareen, J. (2016). Linking typologies of childhood adversity to adult incarceration: Findings from a nationally representative sample. American journal of orthopsychiatry, 86(5), 584.

31. Ross, J., Waterhouse-Bradley, B., Contractor, A. A., \& Armour, C. (2018). Typologies of adverse childhood experiences and their relationship to incarceration in US military veterans. Child abuse \& neglect, 79, 74-84.

32. Saunders, R., \& Lockhart, S. (2020). “TIO: Adverse Childhood Experiences (ACE) Study.” Trauma Informed Oregon, 16 July 2020, traumainformedoregon.org/resources/ adverse-childhood-experiences-ace-study/. Retrieved May 19, 2021,

33. Sawyer, W., \& Wagner, P. (2020). Mass incarceration: The whole pie 2020. Prison Policy Initiative, 24.

34. Schalinski, I., Teicher, M. H., Nischk, D., Hinderer, E., Müller, O., \& Rockstroh, B. (2016). Type and timing of adverse childhood experiences differentially affect severity of PTSD, dissociative and depressive symptoms in adult inpatients. BMC psychiatry, 16(1), $1-15$.

35. Shuler, C. A. (2010). Male victims of intimate partner violence in the United States: An examination of the review of literature through the critical theoretical perspective. International Journal of Criminal Justice Sciences, 5(1), 163.

36. Springe, L., Pulmanis, T., Velika, B., Pudule, I., Grīnberga, D., \& Villeruša, A. (2016). Self-reported suicide attempts and exposure to different types of violence and neglect during childhood: Findings from a young adult population survey in Latvia. Scandinavian journal of public health, 44(4), 411-417. 
37. Steele, H., Bate, J., Steele, M., Dube, S. R., Danskin, K., Knafo, H., ... \& Murphy, A. (2016). Adverse childhood experiences, poverty, and parenting stress. Canadian Journal of Behavioural Science/Revue canadienne des sciences du comportement, 48(1), 32.

38. Tchernegovski, P., Hine, R., Reupert, A. E., \& Maybery, D. J. (2018). Adult mental health clinicians' perspectives of parents with a mental illness and their children: single and dual focus approaches. BMC health services research, 18(1), 1-10.

39. Teicher, M. H., \& Samson, J. A. (2016). Annual research review: enduring neurobiological effects of childhood abuse and neglect. Journal of child psychology and psychiatry, 57(3), 241-266.

40. Tripathi, B. M., \& Lal, R. (1999). Substance abuse in children and adolescents. The Indian Journal of Pediatrics, 66(4), 569-575.

41. Vezzetti, V. C. (2016). New approaches to divorce with children: A problem of public health. Health psychology open, 3(2), 2055102916678105.

42. Westermair, A. L., Stoll, A. M., Greggersen, W., Kahl, K. G., Hüppe, M., \& Schweiger, U. (2018). All unhappy childhoods are unhappy in their own way-Differential impact of dimensions of adverse childhood experiences on adult mental health and health behavior. Frontiers in psychiatry, 9, 198.

43. Whiteside-Mansell, L., McKelvey, L., Saccente, J., \& Selig, J. P. (2019). Adverse childhood experiences of urban and rural preschool children in poverty. International journal of environmental research and public health, 16(14), 2623. 
44. Whitfield, C. L., Anda, R. F., Dube, S. R., \& Felitti, V. J. (2003). Violent childhood experiences and the risk of intimate partner violence in adults: Assessment in a large health maintenance organization. Journal of interpersonal violence, 18(2), 166-185.

45. Yang, J. C., Roman-Urrestarazu, A., \& Brayne, C. (2020). Responses among substance abuse treatment providers to the opioid epidemic in the USA: Variations in buprenorphine and methadone treatment by geography, operational, and payment characteristics, 2007-16. Plos one, 15(3), e0229787. 